\title{
Psychological Evaluation for Images/Videos Displayed using Large LED Display and Projector
}

$\operatorname{AUTHOR}(S)$ :

Nakatsu, Ryohei; Tosa, Naoko; Kusumi, Takashi; Takada, Hiroyuki

\section{CITATION:}

Nakatsu, Ryohei ...[et al]. Psychological Evaluation for Images/Videos Displayed using Large LED Display and Projector. Entertainment Computing - ICEC 2020 2020: 382-390

\section{ISSUE DATE:}

2020

URL:

http://hdl.handle.net/2433/264690

\section{RIGHT:}

This is a post-peer-review, pre-copyedit version of an article published in Entertainment Computing - ICEC 2020. The final authenticated version is available online at: https://doi.org/10.1007/978-3-030-65736-9_34.The full-text file will be made open to the public on 5 January 2022 in accordance with publisher's 'Terms and Conditions for Self-Archiving'.; This is not the published version. Please cite only the published version. この論文は出版社版でありません。引用の際 には出版社版をご確認ご利用ください。 


\title{
Psychological Evaluation for Images/Videos Displayed using Large LED Display and Projector
}

\author{
Ryohei Nakatsu ${ }^{1}$, Naoko Tosa ${ }^{1}$, Takashi Kusumi ${ }^{1}$, and Hiroyuki Takada ${ }^{2}$, \\ ${ }^{1}$ Kyoto University, Yoshida-honmachi, Sakyo-ku, Kyoto, 606-8501 Japan \\ 2 TELMIC Corp., Akiba East Bldg., 1-28-5 Taito, Taito-ku, Tokyo, 110-0016 Japan \\ nakatsu.ryohei@gmail.com
}

\begin{abstract}
Display of images/videos on a big screen/display, such as digital signage, projection mapping, etc., is becoming popular in the area of entertainment, advertisement, and so on. A comparison of the usage of an LED display and a projector is important for such applications. We have prepared an experimental environment where two types of projection/display using a $200 \mathrm{inch}$ LED display and a 200-inch screen and a projector. Also, two brightness conditions, light-on and light-off, and two types of contents, art content and text content were used for the experiment. Under a total of eight types of environments, we carried out a psychological experiment using 24 participants. Each subject filled a questionnaire based on a five-point semantic differential scale. Based on the analysis of the result, it was revealed that the combination of art content, light-off, and LED display gives far better results than other combinations.
\end{abstract}

Keywords: LED display, Projector, Art contents, five scale SD method

\section{Introduction}

Displaying images and videos with a very large scale is suitable as a means to convey image information to many people at the same time. As a method of displaying image or video with a large scale, there are a method of displaying it on a large LED display and a method of projecting it with a projector. Large LED displays are expensive but have excellent visibility even in a bright situation, such as train stations and street corners. On the other hand, the method of displaying it using a projector has the disadvantage that it is difficult to see in a bright situation, but it has the advantage that it can be displayed without changing existing walls or buildings. In particular, projection mapping [1], which projects a three-dimensional image using the shape of a building as it is, has been attracting attention as a new display method of information and is often used in various entertainment scenes.

However, as the price of large LED displays have dropped and the brightness of projectors has improved, it is desirable to accumulate data regarding what kind of information is suitable and what kind of environment is suitable for an LED display and a projector. In this area researches such as how high-resolution display and high-brightness display affect people's psychology [2][3] have been carried out. Also, studies on 
screen size and viewing distance [4] have been conducted. But few experiments have been reported to compare the display by a projector and by an LED display under various conditions. The main reason for this is that a comparison of a large size display with an LED display and a projector is difficult to achieve in an experimental environment at a university. Since we were able to realize such an environment within the framework of joint research with a company, we compared the image/video display of large size when using an LED display and using a projector. At the same time, we compared the LED display and the projector by changing the brightness of the surrounding environment, changing the contents to be displayed, and performed the evaluation using the framework of a psychological experiment. In this paper, the experiment framework, the analysis results, and the consideration based on them will be described.

\section{Method}

\section{$2.1 \quad$ Experimental conditions}

In our experiment, two types of display methods, two types of contents, and two types of brightness conditions were set, and as a result, eight types of experimental conditions were set.

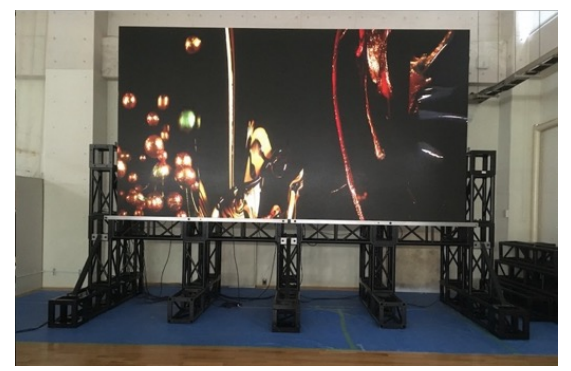

Fig. 1. 200 inch LED display used for the experiment

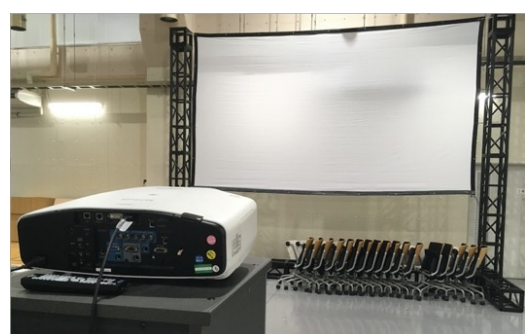

Fig. 2. Screen and projector used for the experiment.

(1) Display method

We compared two methods: displaying contents on a 200-inch LED display and projecting contents on a 200 -inch screen using an 8000 -lumen projector. Figure 1 shows the 200-inch LED display. Also. Figure 2 shows the screen and the projector. The LED 
display, projector, and screen necessary for realizing these environments were installed side by side in a laboratory of about 300 square meters area.

(2) Contents and its creation method

Two types of contents were used for the comparison experiment: a text-based image created using PowerPoint and a video art created by one of the authors, Naoko Tosa. The content of the text-based image is an introduction of a company including text and additional images such as a corporate logo and a representative product. The video art used here is "Sound of Ikebana" created by Naoko Tosa. She found that a fluid such as paint can create flower-like shapes by applying a sound vibration to the fluid and photographing it with a high-speed camera. A speaker is placed face-up, a thin rubber film is put on the top, fluid such as paint is put on it, and the speaker is vibrated with sound, then the paint jumps up and various shapes are created. She found that various fluid shapes can be generated by changing the shape of sound, frequency of sound, the type of fluid, viscosity of fluid, etc. [5]. Then, the obtained video was edited according to the various colors expressing each of the Japanese four seasons to create a video art called "Sound of Ikebana" [6]. This is a video art with a resolution of 4K, with a length of about 30 minutes, and a part of it was used for this research.

In 2014, projection mapping of Sound of Ikebana was performed using the outer wall of Art Science Museum in Singapore with a height of about $20 \mathrm{~m}$. Furthermore, in April 2017, it was exhibited using more than 60 large LED displays in Times Square, New York (Fig. 3). Therefore, the video artwork has a track record of being displayed both using a projector and an LED display and, therefore, is considered suitable for this comparative experiment.

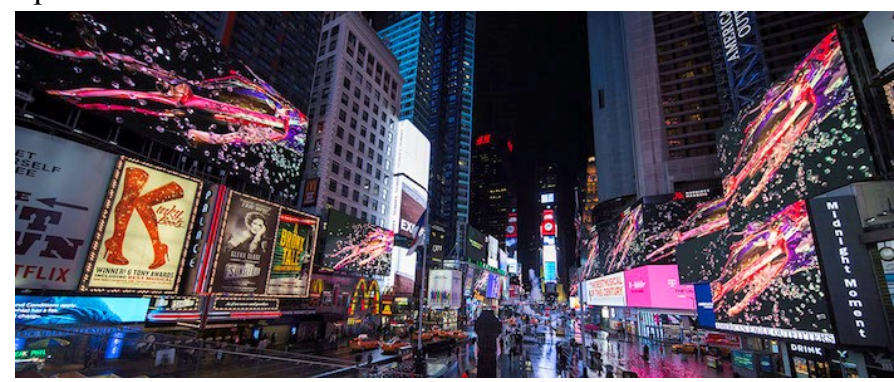

Fig. 3. Exhibition of "Sound of Ikebana" at Times Square in New York.

(3) Environmental conditions

To carry out a comparative experiment between a bright environment and a dark environment, two types of conditions, with and without lighting, were performed in our laboratory. To achieve complete darkness, the experiment was done at night. This made it possible to achieve complete darkness when the lights were turned off. The illuminance of the experimental environment was 40 lux when the light was on and 0 lux when the light was off. During the psychological experiments, the subjects sat down just in front of the LED display or the screen with a distance of $5 \mathrm{~m}$, which is the standard distance when watching a 200 -inch display or screen. 


\subsection{Experimental procedure}

(1) Participants

The participants were 24 students from Kyoto University ( 13 males and 11 females). Their ages were in their twenties, and we considered that the gender ratio should be about half. In the experiment, sufficient informed consent was given to the participants.

(2) Image/video presentation procedure

For each subject, the above mentioned 8 conditions were set in a random order to conduct the experiment. The experiment was repeated 8 times under different conditions with 30 seconds rest $->60$ seconds content display (first time) $->30$ seconds rest -> 60 seconds content display (second time) -> 30 seconds rest as one cycle.

(3) Measuring method

The semantic differential method was adopted as the subjective evaluation method. In this method, adjectives having opposite meanings are placed, and the scale is divided into 7 or 5 point scale. In our experiment, a 5 point scale was used.

(4) Evaluation items

Taking the previous studies [2] [3] [4], etc. into consideration, the six subjective evaluation items shown in Table 1 were selected. When displaying on a large screen, evaluation items such as whether or not a sense of presence is realized were often used [8]. In our case, however, it was decided to use Kansei (sensitivity) evaluation items such as legibility, overall satisfaction, etc. The eight experimental conditions were given in random order, and the questionnaire was filled out at the end of each cycle. After all cycles were completed, a brief interview was conducted with each subject to know their overall impressions.

Table 1. Subjective evaluation items.

\begin{tabular}{cccccc}
\hline \\
Satisfied \\
Easy
\end{tabular}

\section{Results and Discussion}

\subsection{Means and standard deviations}

To compare eight experimental conditions for each subjective evaluation item, means and standard deviations were obtained. The results for each of the six subjective evaluation items are shown in Fig. 4 - Fig. 9. 


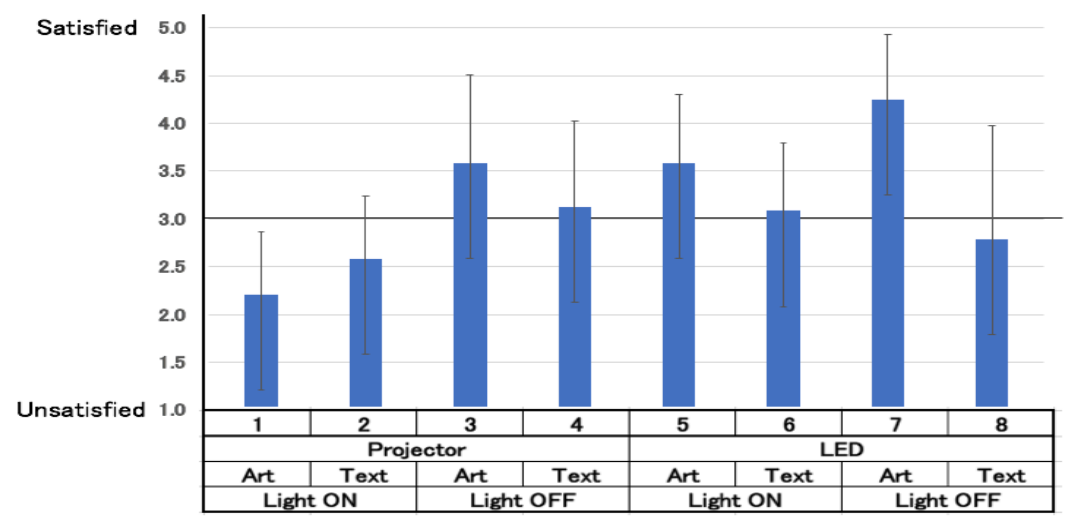

Fig. 4. Comparison of scores for "As a whole were you satisfied?"

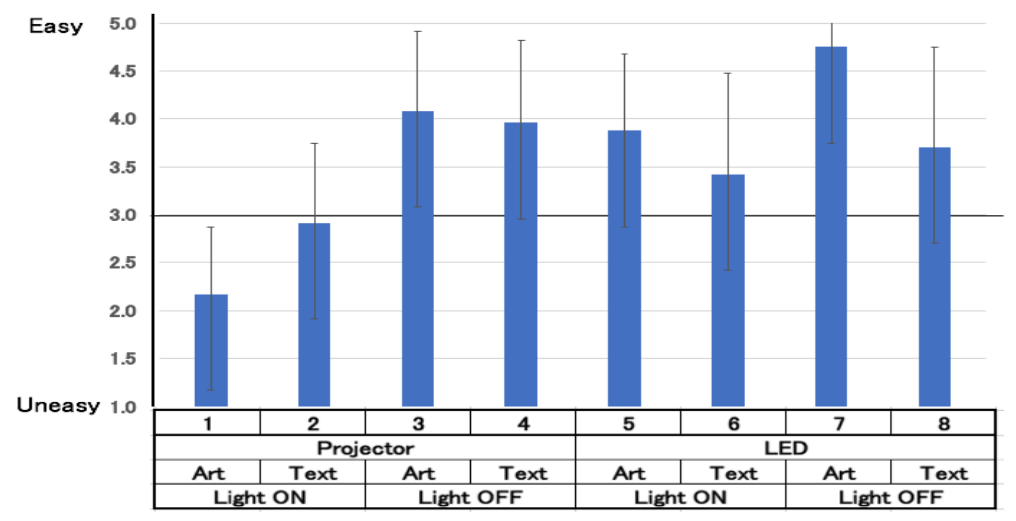

Fig. 5. Comparison of scores for "Was it easy to watch"

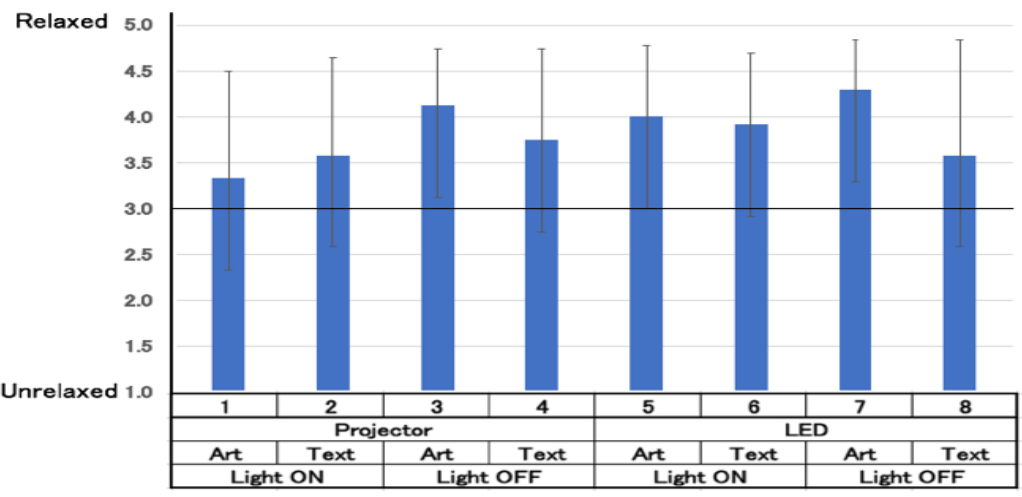

Fig. 6. Comparison of scores for "Were you relaxed while watching?" 


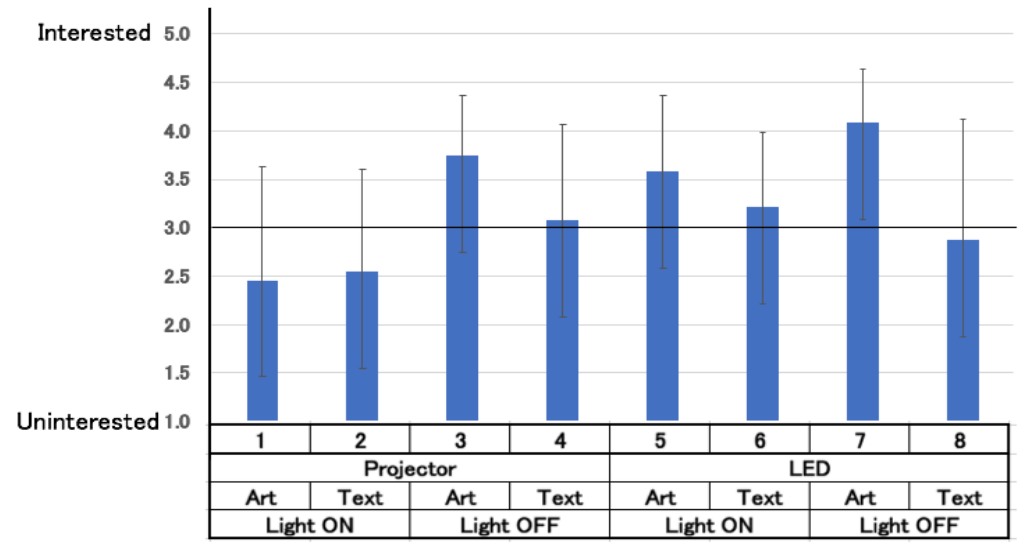

Fig. 7. Comparison of scores for "Were you interested in the content?



Fig. 8. Comparison of scores for "Did you feel elation?"



Fig. 9. Comparison of scores for "Did you want to watch it longer?" 


\subsection{Consideration on scores of each evaluation item}

(1) Total satisfaction

Regarding overall satisfaction, "art x LED x no lighting" is the only one with a score of 4 or higher. The art contents are highly evaluated in the order of "art x LED x no lighting"> "art x projector x no lighting" $\fallingdotseq$ "art x LED x lighting". In particular, "art x LED x no lighting" has been highly evaluated. In the interviews, there were many opinions that details of the art content were highly visible and its power was overwhelming. Only one person replied that under the "art x LED x no lighting" condition, she was tired due to its high contrast. This result shows that the young generation, who are accustomed to watch high-resolution, high-contrast images/videos on smartphones, do not feel awkward when watching an LED display in a dark environment.

Regarding the text, there is a slight difference between "LED x lighting" and "projector x no lighting", and which display method is suitable may depend on the content. As content with text, images, and video mixed together has become quite common in presentations using PowerPoint, it is necessary to perform evaluations when such content is used.

(2) Other evaluation items

Concerning all other evaluation items, "art x LED x no lighting" received the highest evaluation, which leads to the highest evaluation in the overall evaluation. In particular, concerning the ease of viewing the entire image, a score of 4.5 or higher has been obtained. The next highest rating is "art x projector x no lighting". For each evaluation item, "art x projector x no lighting" got the second-highest rating.

When displaying art content such as video art, it is often that the interior is set dark and a sub-content is displayed on the wall using a projector, and at the same time, the main content is displayed using an LED display. One of the authors, Naoko Tosa, has the experience of having such an exhibition at galleries in Japan, Hong Kong, etc. and gained a high evaluation, which supports this result.

Following that, "art x LED x lighting" is highly evaluated. This is also a normal display method for video art in art galleries, but it has received a lower rating compared to "art x LED x no lighting." Based on the results, it can be said that when displaying video art in galleries, etc., it is effective to show art contents by setting the room dark even if an LED display is used.

On the other hand, concerning the display of text-based contents that are commonly used for presentations at academic conferences, etc., the evaluation score is generally low as compared with the display of art contents. However, this is somewhat unavoidable due to the nature of the content itself, and in particular, it is rated lower than art content in terms of "Were you interested in the content?", "Did you feel elation?", "Did you want to watch longer?". On the other hand, concerning "Was it easy to watch", the evaluation comparable to art content was obtained with the evaluation score close to 4 . This supports the fact that in academic conferences usually a room is set dark while displaying content with a projector. 


\section{Conclusion}

When displaying content on a large scale in classrooms, art galleries, conference venues, and entertainment venues, it is an important issue of whether to use an LED display or a projector. Although related research includes research on the psychological effects of high-resolution display and high-brightness display [2][3][4][5], there have been almost no reports of experiments comparing a projector and an LED display under various conditions. Also, the result would depend on a condition, whether the light is turned on or not, whether the displayed content is text-based content or art content.

In this research, we have tackled such a problem. As an environmental condition, we prepared an environment for displaying contents on a large screen of a 200-inch LED display and a 200-inch screen + a projector. We set a total of eight environmental conditions, that is, whether an LED display or projector is used, whether the light is turned on or off, whether the content to be displayed is text-based content or art content. Then we carried out a psychological experiment having 24 subjects to evaluate using the semantic differential method.

As a result, based on the average value of the score, it was found that "art content $\mathrm{x}$ LED x no lighting" got a very high score. It was also found that the commonly used method of "projector $\mathrm{x}$ dark environment" is effective for text-based content. We believe that we have obtained guidelines for display and exhibition regarding whether to use an LED display or a projector and whether to turn on or off the lighting.

For future research, it is necessary to examine in more detail how content differences would affect the results. Also, as it is considered that the sensitivity of the younger generation is reflected in the results, it is necessary to conduct experiments with subjects for other generations.

\section{References}

1. Blokdyk, G.: Projection mapping: A Complete Guide. 5SRARcooks (2018).

2. Sakamoto, K., Sakashita, S., Yamashita, K., Okada, A.: Influence of high-resolution 4K displays on psychological state during content viewing. Proceedings of the $16^{\text {th }}$ International Conference on Human Computer Interaction (HCI) International 2014, pp.363-367 (2014).

3. Sakamoto, K., Yamashita, K., Okada, A.: Effect of high dynamic range on physiological and psychological state during video content viewing. Journal of Human Interface Society, Vol.20, No.2, pp.123-133 (2018).

4. Gilinsky, A. G.: Perceived size and distance in visual space. Psychological Review, Vol.58, pp.460-482 (1951).

5. Narita, N., Kanazawa, M., Okano, F.: Optimum screen size and viewing distance for viewing ultra high-definition and wide-screen images, Trans. of the Institute of Image Information and Television Engineers, Vo.55, No.5, pp.773-780 (2001).

6. Yunian, P., Zhao, L., Nakatsu, R., Tosa, N.: A study on variable control of sound vibration form (SVF) for media art creation. Proceedings of 2015 Conference on Culture and Computing, IEEE Press (2015).

7. Tosa, N., Yunian, P., Qin, Y., Nakatsu, R.: Pursuit and expression of Japanese beauty using technology. Arts Journal, MDPI, Vol.8, No.1, 38 (2019).

8. Heeter, C.: Being there: The subjective experience of presence. MIT Press (1992). 